\title{
Investigating The Causes Of Accident In Construction Site Inwolaita Zone, Southern Ethiopia
}

\author{
EsubalewTariku Yenialem ${ }^{1}$, Wondemagne Tadesse Borku ${ }^{2}$ \\ ${ }^{1}$ Lecturer, Department of Civil Engineering, WolaitaSodo university, Wolaita Sodo, Ethiopia \\ 1Email Id: esubalewtariku@yahoo.com \\ ${ }^{2}$ Lecturer, Department of Construction Technology and Management, Wolaita Sodo university, Ethiopia ${ }^{2}$ \\ Email Id: wondetade@gmail.com \\ *Corresponding Author: Esubalew Tariku Yenialem \\ Lecturer, Department of Civil Engineering, Wolaita Sodo university, Wolaita Sodo, Ethiopia \\ Email Id: esubalewtariku@yahoo.com
}

\begin{abstract}
Construction industry is an important part of the economy in most countries; often seen as a driver of economic growth especially in developing countries. Typically, construction industry contributes significantly to gross domestic products in most developing countries[3]. However, the construction site in Wolaitazone continues to fail to fulfill this fundamental role due to the increased accidents and health hazards. This paper explores the various safety and control measures (SCM) of accidents in building site to minimize accidents"e occurrence and consequent waste generation. A research thesis, consisting of a literature review and a field study were used to achieve the research objectives. The field survey involves a designed questionnaire that was administered through convenience sampling technique within Wolaitazone and descriptive analysis tools were used for the analysis. The field survey reveals different control measures in place and their rate of usage on building site. On the other hand, the literature survey sheds light on the types of accidents on building site and their respective control measures with methodologies for accidents" preventions. Recommendations based on the findings of the two surveys are outlined in the paper.accidents are caused by a wide range of factors, some of which are: -Lack of awareness of safety regulations; Lack of enforcement of safety regulations;Poor regard for safety by people involved in construction projects;Engaging incompetent personnel; non-vibrant professionalism; Mechanical failure of construction machinery/equipment;Physical and emotional stress; andChemical impairment Major causes of accidents identified in this research associated with construction projects include inadequate supervision, use of incompetent personnel and use of inappropriate construction techniques.[18] Among the recommendations made for minimizing and/or avoiding re-occurrence of accidents are review of the existing regulations, enforcement, sensitization and training.
\end{abstract}

Keywords: Accident; Construction site; Causes; safety measures

\subsection{Background of the Study}

\section{INTRODUCTION}

The construction industry is generally defined as economic activities that focus on the construction of physical structures, such as buildings and infrastructure, regardless of the construction being land or marine based. Indeed, the interdependence of the construction sector and economic development has been addressed by various writers and in all cases, there is evidence indicating a direct link between investment in construction and economic growth [6]. The ILO" s global estimates for 2003 indicate that each year at least 60,000 fatal accidents occur on construction sites around the world or one fatal accident in every ten minutes [9]. The more important fact is that most accidents are preventable if proper safety precautions are taken and more caution on health and safety techniques implemented. Most construction companies now have specific safety initiatives, injury-free work-place programs in place, but the threat of accidents still continues to be a concern to the construction industry which therefore necessitates this study [8]. In Ethiopia, just like many other developing countries the construction industry is playing a vital role to achieve socio-economic development goals, providing shelter, infrastructure and employment, and above all contributing significantly to the GDP of the country. Thus, studying the causes of accident in construction projects has gained increasing importance to researchers in the recent years although there is no research conducted before on the topic for Wolaitazone construction site. Wolayita or Wolaita is an administrative zone in Ethiopia. The administrative centre 
of Wolayita is Sodo. Other major towns are Areka, Boditi, Tebela, Bele, Gesuba, Gununo, Bedessa and Dimtu. Wolayita has 358 kilometres of all-weather roads and 425 kilometres of dryweather roads, for an average road density of 187 kilometres per 1000 square kilometres. Its highest point is Mount Damota (2738 meters).

\subsection{Statement of the Problem}

Construction industry is one of the most hazardous industries in the universe because of its unique nature. The construction projects are experiencing so many risks, uncertainties, complexities due to frequently happened accident in construction project [7]. Most of the developed countries trying to reduce the horrific damage and losses from construction accident by preventing eliminate and bypass the possible accident in construction projects [4]. But the developing countries are the extreme victim of construction accident because they have no strict regulation on construction safety and authorities and employee both don"t aware of construction safety issue. Wolaitazone has one of the most accident-prone construction industries among all the developing countries of the world. Wolaitazone construction site experience more death, injury, physical damage of properties[17], risks and complexity than other countries in the world due to the horrific figure of occurring accident and its fatality rate. In wolaitazone construction project. High officials from wolaita zone said "accident in construction site is the topmost serious issue for wolaitazone construction. It is considered as the main barrier of innovation and development of construction industry in wolaitazone. It brings so many complexities in many ways. It is bad; it is really bad for wolaitazone construction site". Construction accidents is the mother of others many problems and complexities in construction project. Failure of adoption and assurance of construction safety against accident in construction project have various affected the project negatively. It is the main cause of project delay, affecting the quality of construction work, decreasing the labor productivity, cost overrun of the, arising dispute between stakeholders, affecting the psychology of worker negatively. Experts said that in wolaita zone there are $80 \%$ construction project experience injuries and death from accidents.[10] The consequences of these accidents go far beyond the particular construction project. Today, it is a basic right of every worker to work a safe and accident-free workplace. For this, at first it is necessary to find out the reason behind construction accident in wolaitazone. To assist the authority and to improve the accident scenario, the main purpose of this study is to investigate, identify and analyze the causes of accident in construction project in wolaitazone. This study may help the authorities and project executives to know and understand about the causes of accident in construction project in wolaitazone. It will also offer some suggestions which can play a vital role to decrease the accident rate and assist the stakeholders to complete construction project successfully with current flow.[11]

\subsection{Objective}

\subsubsection{General objective}

The overall objective of the study was to investigate the Causes of Accidents in the Construction site in wolaitazone. 1.3.2 Specific objective

- To identify accidents in construction site in wolaitazone.

- To classify the major causes of accidents in construction site

- To develop an appropriate program/guideline for safety in the construction process.

\subsection{Research questions}

The following research questions were formulated to further examine the causes of accidents in construction site in Wolaitazono:

- What types of different accidents in construction site exist?

- How can to classify the major causes of accidents in construction site in Wolaita zone?

- How can to develop an appropriate program/guideline for safety in the construction process.

\subsection{Accidents}

\section{REVIEW OF LITERATURES}

Accidents are unplanned or unforeseen occurrences that result in injuries, and cause unexpected damages. These accidents are, however, unavoidable in the industry and remain the main disadvantage in the construction industry. According to Chong \& Low, the inherent hazards and the nature of the activities of the construction industry contribute to occupational injuries. Furthermore, Chong \& Low also emphasized that there are three types of hazards which need to be recognized and controlled in all industries, especially in the construction industry: chemical, physical and biological [2]. 


\subsection{Types of accidents}

\section{Slips and falls}

Accidents due to Slip \& Fall (due to tripping, slipping, or sitting, fall from equipment, jumps to lower level) are the most common accidents causes in construction projects. Authors investigated the accidents due to fall from a higher level, Falls, slips, falls to lower level, fall from collapsing structure or equipment, fall through surface or existing opening, leaps to bring down level, the conversation of referenced mishapse ${ }^{\text {ec }}$ reasons demonstrated that China development organizations have encountered a bigger number of Accidents in their projects than United States and South Korea development organizations [13].

\section{Machinery}

Machinery related accidents are very common accidents in construction industry. Authors investigated accidents due to vehicles, machines and loss of control of machines.

\section{Laboure}

Accidents due to Laboure issues are the most common accidents issues in construction industry around the world.Authors reported the different causes of accidents due to lack of training. They focused on Chinese Construction Accidents of completed projects. These projects were initiated by Application of Accidents Analysis methods by Chinese Construction Accidents. Authors investigated the accidents due to lack of technical work staff training, poor site management, recruitment of older worker in construction Industry, which can cause and can affect execution plan of construction project. The major causes of construction accidents were identified and ranked accordingly. The proposed method was used for the maintenance and rehabilitation of streets and entrances to neighborhoods [2].

\section{Equipment}

Accidents due to Faulty equipment, Misplacing objects, Defective machinery onsite and Defective forklift are known as Equipment Related Accidents that cause the projects failure.[8].

\section{Team Issues}

Lack of team work training, inadequate construction planning and scheduling, Supervisory faults, Lack of knowledge/skills of job are the team issues which cause accidents in a construction project. While site management of a construction contract cannot control the Accidents, they should anticipate the possibility of adverse accidents and address it in their contracts. Team issues accidents can impact on construction projects.[Haslam].[18]

\section{Scaffolding/Ladder}

Accidents due to improper use of Scaffolding \& Ladders are very common in construction Industry. These accident are caused due to Scaffolding not properly installed, or may be inappropriate use of ladders and hoists, due to collapse of scaffold leading to damages of adjacent property and mostly due to loose bonding of scaffolding[3].

\section{Site Condition}

Site conditions issues vary from project to project. Accidents due to site unforeseen conditions are caused due to site management, less safety methods and project related effects on site conditions (e.g. wet slippery floors, Unstable stacking of materials, Poor storage combustible materials)[1].

\subsection{Causes of Accident [2]}

Common causes of construction site accidents include:

- Lack of fall protection for workers on elevated structures

- Lack of protection for people on the ground from falling objects

- Tripping hazards from construction materials and debris

- Missing guards or protections on power tools

- Unsafe equipment

- Lack of safety precautions when working near power lines

- Lack of protection for workers in trenches

- Unsafe property conditions 


\subsection{Effects of Accident [2]}

- Suffering to individual

- Hardship to the individual

- Fatality

- Minor injury

- Disabling injury

- Possible loss of earning the ability

- Production delay

- Increment in insurance premium

- Legal expenses

- Time lost by the employee

- Reduced quality

- Time spent in training a temporary or permanent replacement

- Legal liability

- Failure to safeguard employee being a criminal offense leading to prosecution

\section{RESEARCH METHODOLOGY}

\subsection{General}

The study area is wolaitazone which is located in southern parts of Ethiopia. Wolaita zone is the capital city of wolaita zone which is one of zone of South Nation and Nationalities People Region. [14]

\subsection{Method of Data Collection}

In order to meet the objectives of the study, a concise method of data collection has to be devised and implemented to get a reasonable quality output. We used two methods of data collection; those are:

- The primary data: Consists of study and questionnaire on causes of accident in construction site and its safety measures.

- The secondary data: Literature review on many related issues from the different published and unpublished sources will be collected to get enough information on such related issues and from internet and referring other related documents.[16]

\subsection{The Research Questionnaire Design}

The questionnaire design was based on a combination of an extensive review of literature dealing with the causes of accidents in construction site and its safety measures. [19]

The questionnaire, which was accompanied by a cover letter, consisted of three parts. The questionnaire was a mix of structured (closed) and unstructured (open) type of questions.

\subsection{Rationale of the Research Questionnaire}

A questionnaire consisted of three sections are prepared to investigate causes of accident in construction site on wolaitazone. The questionnaire is designed to extract information based on the actual practice in the projects rather than opinion based.

The first section contained questions to evaluate the judgment of the acting superintendent on the projects based on his experience on building construction projects.

Section two contained questions which are designed to extract information about the selected building projects, which includes the stakeholders of the project, the total project duration and cost, geometry of the building, etc. It will provide detail information on safety application and operation of accident on construction site.[15]

3.5 Respondent's work position and Experience Distribution of respondent's work position on the projects, years of experience in the construction industry and no building projects they have worked in the past are illustrated on table 5 below. 
Table 1 Respondent's work position and Experience

\begin{tabular}{|c|c|c|}
\hline \multirow[t]{2}{*}{ Respondents work Position \& Experience } & \multicolumn{2}{|l|}{ response distribution } \\
\hline & Frequency & \\
\hline \multicolumn{3}{|l|}{ job title } \\
\hline Contractor & $\varepsilon$ & 28 \\
\hline Consultant & ? & 32 \\
\hline Workers & 1( & 40 \\
\hline Total & 2 & \\
\hline \multicolumn{3}{|l|}{ experience } \\
\hline $0-3 \mathrm{yr}$ & & 20 \\
\hline $4-6 \mathrm{yr}$ & & 28 \\
\hline $7-10 \mathrm{yr}$ & & 32 \\
\hline$>10 \mathrm{yr}$ & & 20 \\
\hline Total & & \\
\hline \multicolumn{3}{|l|}{ worked projects } \\
\hline $0-4$ & & 24 \\
\hline $5-7$ & & 32 \\
\hline $8-10$ & & 24 \\
\hline$>10$ & & 20 \\
\hline Total & & \\
\hline
\end{tabular}

\section{RESULTS AND DISCUSSION}

\subsection{Causes of Accident}

We investigated causes of accident in construction site in wolaitazone, categorized by relating it to 11 major group, and watch by detail.

\begin{tabular}{|c|c|c|c|}
\hline no & relating & causes of accident & Rank \\
\hline \multirow{4}{*}{1} & \multirow{4}{*}{ project related } & Poor Planning/ scheduling of project & 3 \\
\hline & & Very tight project schedule & 2 \\
\hline & & Type and nature of project & 1 \\
\hline & & Social and communal involvement of project & 4 \\
\hline \multirow{4}{*}{2} & \multirow{4}{*}{$\begin{array}{l}\text { site condition } \\
\text { related }\end{array}$} & Project site conditions & 3 \\
\hline & & Project site layout/space & 4 \\
\hline & & Project working environment & 2 \\
\hline & & Poor housekeeping & 1 \\
\hline \multirow{4}{*}{3} & \multirow{4}{*}{ design related } & Design is not constructible & 3 \\
\hline & & Incomplete and inconsistency of design document & 4 \\
\hline & & Safety is not considered when design & 2 \\
\hline & & Lack of safety eliminating/ avoiding design & 1 \\
\hline \multirow{3}{*}{4} & \multirow{3}{*}{ material related } & Lack of protection in material storage & 1 \\
\hline & & Working with toxic/ hazardous materials & 3 \\
\hline & & Hazard during transportation & 2 \\
\hline
\end{tabular}




\begin{tabular}{|c|c|c|c|}
\hline & & Lack of knowledge about construction materials & 4 \\
\hline \multirow{3}{*}{5} & \multirow{3}{*}{ cost \& time related } & Cost overrun reduce the safety cost & 3 \\
\hline & & Schedule delays and rework in project & 2 \\
\hline & & Short time assign to worker & 1 \\
\hline \multirow{5}{*}{6} & \multirow{5}{*}{ consultant related } & Lack of Management/ leadership skills & 3 \\
\hline & & Lack of knowledge and experience & 5 \\
\hline & & Unaware of construction safety & 2 \\
\hline & & irregular investigation & 1 \\
\hline & & No interest to change the safety culture & 4 \\
\hline \multirow{5}{*}{7} & \multirow{5}{*}{ contractor related } & Inaccurate or incomplete schedule & 4 \\
\hline & & Unaware of safety related issue & 1 \\
\hline & & Unwilling to spend safety related cost & 2 \\
\hline & & Lack of skill and experience of site staff & 5 \\
\hline & & Violating ethiopialabour law & 3 \\
\hline \multirow{6}{*}{8} & \multirow{3}{*}{ workers related } & Lack of collaboration among labours & 5 \\
\hline & & Lack of personal protective equipment & 1 \\
\hline & & Unskilled labours & 3 \\
\hline & & Poor of education of labourers & 6 \\
\hline & & Lack of Expertise, knowledge or training & 2 \\
\hline & & Behaviour of worker & 4 \\
\hline \multirow{5}{*}{9} & \multirow{5}{*}{ owners related } & Unwilling to pay extra cost for safety & 1 \\
\hline & & Owner"s interference on schedule and process & 4 \\
\hline & & Owner"s expectations variation & 5 \\
\hline & & Lack of owner"s emphasis on safety & 3 \\
\hline & & owneres late response ( decision making) & 2 \\
\hline \multirow{5}{*}{10} & \multirow{5}{*}{$\begin{array}{r}\text { equipment } \& \\
\text { tool related }\end{array}$} & Unfit equipment & 2 \\
\hline & & Poor equipment maintenance & 5 \\
\hline & & Unused of modern equipment & 4 \\
\hline & & High cost of advanced equipment and tools & 3 \\
\hline & & Improper use of equipment & 1 \\
\hline \multirow{4}{*}{11} & \multirow{4}{*}{ technology related } & Unused of safety control system & 1 \\
\hline & & Unused of schedule system & 4 \\
\hline & & Unaware to advanced technology for safety & 3 \\
\hline & & Lack of innovation technology & 2 \\
\hline
\end{tabular}

Table 3 Respondent Ideas on Causes of Accident

\begin{tabular}{|r|l|r|r|}
\hline rank & causes of accident & responses & $\%$ \\
\hline 1 & Bad attitude to work Safety & 24 & 96 \\
\hline 2 & Lack of Health \& safety training of workers & 22 & 88 \\
\hline 3 & Inadequate Equipment \& Tools & 21 & 84 \\
\hline 4 & poor Working conditions and environment & 20 & 80 \\
\hline 5 & Tiredness of Workers & 18 & 72 \\
\hline 6 & Lack of Communication & 16 & 64 \\
\hline
\end{tabular}




\begin{tabular}{|r|l|r|r|}
\hline 7 & Lack of Appropriate Skills & 15 & 60 \\
\hline 8 & Low level of Education & 13 & 52 \\
\hline
\end{tabular}

From the table 4 above we observe that $96 \%$ of respondent projected their ideas on the causes of accident is bad attitude to work safety, $88 \%$ said that it is lack of health and safety training of workers, and they said inadequate equipment and tools, poor working conditions and environment, tiredness of workers, and so on. [17]

\subsection{Remedial Measures}

- Falls from high height or scaffolding

- codes and standards in all construction sites

- Emphasis on the importance of health and safety training for staff

- Ensuring the different people with duties under the Health and Safety

- Employment Act are aware of their duties and what they need to do to fulfill those obligations

- Ensuring people working within a contracting environment are adequately

- protected Awareness of an increased risk of fatality when working over 3 meters in height

- Awareness about testing the structural integrity of permanent and temporary structures

- Awareness of correct use and maintenance of safety equipment designed to prevent falls When erecting a mobile tubular scaffold on an inclined floor

- suitable mats should be used to keep the scaffold in a level position

\section{Slips, trips, and falls}

- Create Good Housekeeping Practices

- Reduce Wet or Slippery Surfaces

- Avoid Creating Obstacles in Aisles and Walkways

- Create and Maintain Proper Lighting

- Wear Proper Shoes

- Control Individual Behavior

- Getting Caught In Between Objects or Materials

- Ensuring all safety measures is in place after any equipment or machinery has been overhauled.

- Avoiding misbehavior while at work.

- The wheels of machines or equipment should be wedged properly to prevent movement.

- Concentrating on the task at hand and the people around the work area.

- Avoid working with equipment or machines braced with jacks.

- Switching off equipment and machines before

- Being extra cautious while working with machines or equipment with gears, cables, straps, pulleys, or drive shafts.

- Escape route should be defined to avoid getting sandwiched between two objects.

\section{Fires and explosion}

- Provide access to firefighting equipment at all times, and regularly inspect firefighting equipment

Provide a water supply of sufficient volume, duration, and pressure to operate

- firefighting equipment

- Where underground water mains are to be provided, they must be installed and available for use as soon as practicable during the construction process, and if a building includes a sprinkler system, it must be installed as soon as possible

- There must be at least one fire extinguisher on every floor and enough fire extinguishers present that worker do not have to go more than 100 feet to retrieve one when needed (but sometime a hose may substitute)

- Fire walls and exit stairways shall be given construction priority over other jobs

- Fire alarm systems are required

\section{Machinery accidents}

- provide the correct type of work equipment which is suitable and safe for the job

- properly maintain and safety inspect work equipment

- provide proper training and information to any employee using equipment at work 
- ensure that the work equipment is fitted with suitable safety features (for example emergency stop controls, guards, warning signs etc)

\section{CONCLUSION}

Generally, the production of construction products is a risky, complex and lengthy process. Cost, time, quality and safety are important characteristic of every project. Adherence to safety requirements has led to increased exposure of workmen and the general public to risky situation at construction sites resulting in a high chance of occurrence of accidents. Accidents resulted direct physical injury to persons or damage to property, but also short- and long-term effects to the company. The aim of this study to know safety problems causes of accidents and injuries on construction site. The cause of accidents in the construction industry like workers"e negligence, failure of workers to obey work procedures, work at high elevation, operating equipment without safety devices, poor site management, harsh work operation, low knowledge and skill level of workers, attitude about safety. All organizations and individuals involved in construction projects should be actively concerned with the safety of the workers performing the actual construction onsite. Establishing realistic, shared expectations about the safety role that each entity can play will reduce the current uncertainty within the design and construction community, allowing entities to better focus on the roles they can realistically assume. Ultimately, shared expectations will help prevent some accidents from occurring and improve the overall level of safety on construction sites.

\section{REFERENCES}

[1] Miss.Smita .A. Bhole (2016) "Safety Problems and Injuries on Construction Site" Volume 2 Issue 4, July Aug 2016.

[2] PanassayaPromsorn, ParichatSoponsakulrat (2015) "Identifying Root Causes of Construction Accidents" Vol. 2, Issue 1 (2015) ISSN 2349-1469 EISSN 2349-1477.

[3] Abdul Rahim, Abdul Hamid (2008) "Causes Of Accidents At Construction Sites" Vol.2 20(2) : 242 - 259 (2008).

[4]. T.Dejus (2008) “Accidents On Construction Sites And Their Reasons” Vol.2 No. 03, pp[35-44]

[5] Dr.A. Paulmakesh, Dec 2021, "Analysis of uncertainty in a construction project" YMER journal, Vol 20,Issue 12, pg.no 324-332.

[6] Dr.A. Paulmakesh, Gizachew Markos Makebo April 2021, "Management of contracts for Durable structures" Innovations, Number 64,Pg 1044-1054

[7]. RaymondKemei, Julius Nyerere (2016) "Occupational Accident Patterns and Prevention Measures in Construction Sites in Nairobi County Kenya” 2016; 4(5): 254-263 ISSN: 2330-8729 (Print); ISSN: 23308737.

[8]. Ravi Patel, UrveshBarot, Keyur Shah (2013) “ Accident On Construction Site: Identification \&Mitigationa” vol.5 pp.231-125 ISSN : 2394-1766.

[9] Yimam Mohammed, A. Paulmakesh, Bereket Admasu amd Saliha Shukri, Oct 2021, "Relationship between California Bearing Ratio and Other Geotechnical Properties of Sub grade Soils", ICEPAE 2021,Journal of Physics Conference Series, Vol 2040(1):012024, doi:10.1088/1742-596/2040/1/012029, pg.no 1-13.

[10]. EduardoDiniz Fonseca, Francisco P.A. Lima , Francisco Duarte (2014) "From Construction Site To Design: The Different Accident Prevention Levels In The Building Industry" Safety Science 70 (2014) 406-418.

[11]. W.A.Asanka and M. Ranasinghe (2015) "Study on the Impact of Accidents on Construction Projects" vol.4 pp. 28802288

[12] StigWinge, EirikAlbrechtsen 2015 "Accident types and barrier failures in the construction industry", Safety Science, 105(1), pp.158-166.

[13] StigWinge, EirikAlbrechtsena, BodilAamnesMostue, 2019 "Causal factors and connections in construction accidents" Safety Science, 112(1), pp.130-141.

[14] Bozena Hola, Mariusz Szostakin, M. Tomasz Nowobilkiski, IwonaSzer, JacekSzer, 2017. "Methodology of analyzing the accident rate in the construction industry". Procedia Engineering, 172(3), pp.355-362.

[15] Shakti Ganesh. G, Rajesh. M (2017), „A Study on Identification of Causes and Effects of Accidents in Constriction Industry- Indian Scenario"e, SSRG International Journal of Civil Engineering, Vol.4, pp. 42-48. 
[16] Dr.A. Paulmakesh, Yimam Mohammed Yimer April 2021, "Implementation of Project Management for Strategy Realisation" Journal of University shanghai for Science and Technology, Volume 23, Issue 10,Pg.No 887-892

[17] Jongsik Lee1, Myungkwan Lim (2017), ,Analysis on the Degree of Risk According to the Causes of Accidents in Construction Projects in Korea ${ }^{e e}$, International Journal of Applied Engineering Research, Vol. 12, pp. 28212831.

[18] StigWinge, EirikAlbrechtsen (2018), „Accident Types and Barrier Failures in the Construction Industry“, Safety Science Vol. 105, pp. 158-169.

[19] Yimam Mohammed Yimer, A. Paul Makesh and SalihaShukri Muhammed, Oct 2021, "Prediction of undrained shear strength and correlation in between soil parameters", ICEPAE 2021, Journal of Physics Conference Series, Vol 2040(1):012029, doi:10.1088/1742-6596/2040/1/012024 pg.no 1-8. 